\title{
Integração da gestão de recursos hídricos: caso da bacia hidrográfica Mebre-Sorge, cantão de Vaud, Suíça
}

\section{Graziele Muniz Miranda}

Recebido: 19/09/13

revisado: $12 / 11 / 13$

aceito: $12 / 03 / 14$

RESUMO: A gestão integrada de recursos hídricos por bacia hidrográfica visa ao controle do estado dos corpos hídricos, considerando sua interaçáo com os usos e os atores de uma mesma bacia hidrográfica e a coordenação entre os níveis institucionais nacional, regional e local. Em diversos países, sobretudo na Suíça, sua regulamentação e aplicação é atualmente discutida. Nesse âmbito, esta pesquisa analisa a integração da gestão de recursos hídricos na Suíça através do estudo de caso da bacia hidrográfica Mèbre-Sorge, cantão de Vaud, que apresenta um quadro de forte urbanização e artificializaçáo dos mananciais. Assim, foram utilizados indicadores segundo a integração entre atores e usos, atores e recursos hídricos e entre as escalas federal, regional e local através de entrevistas com os principais atores institucionais ligados à bacia. A aplicaçáo dos indicadores evidenciou a falta de integração entre os principais usos e atores na área de estudo. Náo existe um organismo ou um acordo englobando todos os setores nem uma estrutura formal que favoreça a gestão integrada de recursos hídricos a nível cantonal ou local. Assim, a gestão é realizada setorialmente e a curto prazo.

PALAVRAS-CHAVE: gestão integrada de recursos hídricos, indicadores, bacia hidrográfica.
ABSTRACT: The integrated management of water resources by basin aimed at control of the state of water bodies, considering its interaction with the actors and uses the same basin and coordination between institutional levels national, regional and local. In many countries, especially in Switzerland, its regulation and enforcement are currently discussed. In this context, this research examines the integration of water resources management in Switzerland through the case study watershed Mèbre-Sorge, Canton of Vaud, which provides a framework for strong urbanization and artificiality of the springs. Thus, indicators were used according to the integration between the actors and uses actors and resources water and between scales federal, regional and local level through interviews with key institutional actors attached to the bowl. The application of the indicators showed a lack of integration between the main actors and uses in the study area. There is no body or an agreement encompassing all sectors or a formal structure that favors the integrated management of water resources at cantonal or local. Thus, management is performed by sector and short-term.

KEY WORDS: Integrated management of water resources, indicators, watershed.

\section{INTRODUÇÃO}

As variações do estado dos corpos hídricos estão ligadas aos fatores de ordem natural (hidrologia, climatologia e geomorfologia), aos impactos referentes aos usos e aos atores concernentes à bacia hidrográfica em questão. Dessa forma, tais alterações demandam a coordenação entre os atores ligados aos diversos usos na bacia hidrográfica visando a sua proteção, controle e mediação de conflitos.

Nesse sentido, a aplicação da gestão integrada de recursos hídricos (GIRH) por bacia hidrográfica é considerada como um importante instrumento, pois considera as interações entre os recursos e os usos nas escalas local, regional e global (Reynard, 2008). Atual- mente ela vem sendo discutida ou mesmo incorporada na legislação ambiental de países, como o Brasil e a Suíça.

A Suíça, considerada o "castelo de água europeu" (ConventionAlpine, 2009) possui alta qualidade e disponibilidade hídrica provinda dos Alpes. Entretanto, diversos corpos d'água foram retificados no século passado e atualmente quase $15.000 \mathrm{~km}$ são considerados pelo governo como estando em mau estado (Office Fédéral de l'Environnement, 2013). Devido a isso, o governo Suíço preocupa-se sobretudo com a proteção contra enchentes e a qualidade de suas águas. A Confederação, os cantões e as comunas (como pequenas cidades) engajam-se em inúmeros programas, projetos de pesquisa e acordos de conservação e renaturalização dos corpos hídricos. 
A aplicação da GIRH por bacia hidrográfica é atualmente um ponto central e fortemente discutido no país. Mas, apesar de ser consenso por parte do governo (evidenciado por inúmeros seminários, incitações e documentos vindos do órgão federal responsável pelo meio ambiente (Office Fédéral de l'Environnement, 2007a, 2007b, 2010, 2011, 2013) e de especialistas na área (Canneva\&Guérin-Schneider, 2011, Charnay, 2010, GWP, 2000, Kenmogne et al., 2010), possui dificuldades de implantação, evidenciadas sobretudo pela sua não obrigatoriedade legal.

Como conceito, a GIRH pode ser mensurada por meio de indicadores. Estes constituem uma ferramenta que permite avaliar em qual medida os governos locais são capazes de responder às pressões ligadas aos recursos hídricos. Dessa forma, é possível comparar as diferentes situações e confirmar (ou negar) as escolhas e as prioridades dos investimentos.

Muitas instituições e pesquisadores utilizam indicadores de sustentabilidade ou de gestão ambiental para fazer análises em diferentes escalas (Appleton et al., 2000 ; Faucheux\&Nicolaï, 2004; Van Bellen, 2005 ; PNUMA 2003 ; Bell \& Morse ; 2008 ; Souto, 2012). Mas a maioria desses estudos se limitam a uma análise da gestão da água, enquanto outros ao setor de gestão ambiental ou à evolução do desempenho da gestão. A avaliação da aplicação do conceito de gestão integrada de recursos hídricos é relativamente pouco desenvolvida.

Este artigo apresenta os resultados da pesquisa realizada na Université de Lausanne, Suíça, durante o período de setembro a junho de 2013 através de financiamento da Confederação Suíça. Brevemente, mostra a situação atual da gestão de recursos hídricos no país e expõe a metodologia criada para avaliação do processo de integração na gestão de recursos hídricos na Suíça, tomando como exemplo a bacia hidrográfica Mèbre-Sorge, no cantão de Vaud.

\section{GESTÃO INTEGRADA DE RECURSOS HIIDRICOS POR BACIA HIDROGRÁFICA}

Simplificadamente, a gestão de recursos hídricos é a forma de tratar a influência antrópica sobre os mananciais (OFEV, 2007a). Assim, ela visa administrar os múltiplos usos dos recursos hídricos, a proteção ambiental e a prevenção e a defesa contra eventos extremos.

Os usos dos recursos hídricos são múltiplos e variam segundo as características sociais, econômi- cas e culturais das sociedades. Além disso, em um mesmo manancial os usos podem ser concorrentes, como o uso pesca e o uso energia elétrica, pois enquanto este altera o curso natural do rio, aquele pode sofrer os impactos com a minimização de peixes. Assim, os diferentes usos, conduzidos por diferentes atores, interagem direta ou indiretamente na bacia hidrográfica.

A gestão ambiental (compreendendo também a de recursos hídricos) foi realizada durante longo tempo segundo respostas imediatas dos governos às perturbações ambientais. Além disso, o início de projetos de gestão de recursos hídricos em diferentes países desenvolveu-se de maneira centralizada e por setores de interesse.

A consideração da bacia hidrográfica em detrimento de outros limites, como administrativo, durante o processo de gestão de recursos hídricos é um grande avanço para a descentralização da gestão. Entretanto, não significa necessariamente que todos os usos estejam coordenados, dependendo da realidade institucional refletida pelo reconhecimento e integração entre os sistemas meio ambiente, atores e escalas de gerenciamento. No Brasil, ela é adotada como unidade territorial para implantação da gestão de recursos hídricos desde 1997. Todavia, atualmente ainda são flagrantes casos de conflitos e dificuldades para sua prática (Araujo et al., 2012).

A gestão integrada de recursos hídricos (GIRH) por bacia hidrográfica visa à coordenação entre diferentes usos e atores na escala da bacia hidrográfica, suas influências sobre o meio ambiente e sua articulação entre os níveis local, regional e nacional (Reynard, 2008).

A GIRH possui diversos convenientes (OFEV, 2012), dentre os quais :

adaptação: pode ser adaptada de acordo com cada sistema hídrico em termos de perímetro, organização e necessidades dos atores;

sustentabilidade: a bacia hidrográfica é o local de referência de acordo com o sistema natural e onde ocorrem as interferências sociais e econômicas;

eficácia: utiliza eficazmente, através dos processos de planejamento e decisóes intersetoriais, os meios a disposição e aproveita-se da economia de escala;

prioridade: a cooperação entre os atores relacionados à bacia hidrográfica permite organizar as prioridades em escala local. 


\section{Gestão de recursos hídricos na Suíça}

Assim como o Brasil, a Suíça é um país federal. Desse modo, a gestão é realizada de forma complexa e cada ente governamental possui seu papel na gestão das águas. Ela é feita de maneira descentralizada entre a Confederação, os cantões e as comunas.

De acordo com o artigo 76 da Constituição Federal suíça, a Confederação se ocupa: dos princípios que regem a utilização e a proteção das águas; dos princípios de uma utilização racional dos recursos; das disposições relativas à proteção das águas e à luta contra ações que degradem as mesmas. Essas funções estão de acordo com suas competências gerais em matéria de proteção do ambiente natural e sua responsabilidade no domínio de exploração de recursos naturais. Deve-se igualmente ao fato que o ciclo da água ultrapassa os limites cantonais e que a gestão das águas requer uma regulamentação uniforme.

Inúmeras leis suíças ligadas à gestão de águas são editadas com base na Constituição Federal. Entretanto, não existe uma lei única sobre a gestão de recursos hídricos, mas sim uma grande variedade de leis setoriais sobre os temas: pesca (LFSP), proteção contra enchentes e ordenamento dos corpos hídricos (LACE), utilização das forcas hidráulicas (LFH) e proteção das aguas (LEaux). Segundo Office Fédéral de l'Environnement (2007), em 1980, visou-se uma legislação global sobre a gestão de águas, mas ela foi abandonada pela comissão encarregada de elaborá-la.

Os cantões possuem um importante papel na gestão de recursos hídricos, pois abarcam o poder legal sobre estes e podem criar regulamentações. A organização e o conteúdo destas variam de um cantão a outro, assim como a repartição das funções. Mas a maior parte dos cantões possuem leis de proteção das águas e de utilização das forças hidráulicas.

Genebra e Friburgo são exemplos de cantões que possuem leis específicas para a aplicação da gestão integrada de recursos hídricos por bacia hidrográfica. Mas são minorias, pois grande parte dos cantões no país não estão organizados nem possuem lei específica para aplicar a GIRH.

O cantão de Genebra está localizado em zona fronteiriça com a França e possui convenções, protocolos e memorandos voltados à gestão de águas com este país (Genève, 2013). Além disso, possui desde 1961 uma lei sobre águas (Genève, 1961) fixando os objetivos de qualidade de água, sua utilização e proteção e gerenciamento de sistemas de evacuação e tratamento de águas.
O cantão de Friburgo conta com a lei sobre as águas (Fribourg, 2009), seguida por sua regulamentação (Fribourg, 2011). Graças a essa lei, a gestão integrada de recursos hídricos está em vias de ser aplicada através da criação de três serviços relacionados: Serviço de Meio Ambiente (para proteção e qualidade da água), Serviço de Canais e Portos (para o ordenamento e a utilização da água) e o Serviço de Segurança Alimentar e Veterinária (para a qualidade da água potável e alimentos). Além disso, a gestão de águas no cantão é realizada por bacias hidrográficas através da associação de comunas e apoio do cantão.

As comunas suíças dispõem de autonomia dentro dos limites fixados pelo direito cantonal. $\mathrm{Na}$ maioria dos cantões, elas assumem importantes atividades no setor, como: abastecimento de água, tratamento de água e esgoto, aproveitamento de energia hidráulica, etc. Entretanto, a repartição das funções varia de um cantão ao outro (OFEV, 2007b).

A gestão integrada de recursos hídricos por bacias hidrográficas é estimulada por numerosos manuais e relatórios que são editados frequentemente pela Confederação. O Office Fédéral de l'Environnement (OFEV) publicou recentemente, dentre outros: Gestão de águas na Suíça: situação atual e teses (2007a); Descrição e análise de exemplos de gestão integrada por bacia hidrográfica (GIB) (2007b); Gestão por bacia hidrográfica: ideias diretrizes (2011); Gerir as carências locais de água na Suíça (2012), etc. Porém, na maior parte dos casos, ela é realizada de maneira setorial, de acordo com a ocorrência de problemas ambientais.

\section{MATERIAL E MÉTODOS}

Com base na gestão de recursos hídricos na Suíça, a presente pesquisa se compõe das seguintes etapas metodológicas:

Análise documental e identificação de atores foram realizadas leituras relativas a gestão de águas na Suíça de acordo com a legislação específica, relatórios e documentos da OFEV e teses para ter-se uma compreensão do estado da arte no país. Em seguida, privilegiou-se leituras de documentos ligados à bacia hidrográfica Mèbre-Sorge e à identificação dos atores envolvidos segundos os usos existentes na bacia em questão.

Elaboração de uma metodologia para avaliação da GIRH por bacia hidrográfica - Uma primeira lista de indicadores foi elaborada após as leituras realizadas. Para auxiliar a triagem/modificação dos 
indicadores a fim de medir o nível de integração da gestão de recursos hídricos por bacia hidrográfica, foram entrevistados os seguintes especialistas: Phillip Hohl (chefe da Divisão de águas na Direção de Meio Ambiente do cantão de Vaud), LuziusThomi e Christophe Joerin (respectivamente chefe do Setor de Estudos e Planejamento e chefe do Serviço de Pontes e Canais, ambos do cantão de Fribourg) e Luca Rossi (colaborador científico sênior no setor de hidrologia da ÉcolePolytechniqueFédérale de Lausanne-EPFL). Para cada entrevista, apresentou-se uma ficha precisando o contexto, a problemática, os objetivos e a metodologia da pesquisa.

Seleção dos indicadores - Os indicadores selecionados foram divididos em três tipos de integração: 1 . Entre atores e usos; 2. Entre usos e meio ambiente; 3 entre as escalas de gestão local, regional e nacional. Os indicadores podem ser visualizados no Quadro 1.

Aplicação dos indicadores da integração da gestão de recursos hídricos nas bacias hidrográficas Mèbre-Sorge, Suíça - entrevistas foram realizadas com os principais atores ligados à gestão de recursos hídricos na bacia hidrográfica para obtenção dos resultados. Os cinco atores institucionais (cantonais e comunais) contatados eram responsáveis pelos setores de tratamento de água e esgoto, água potável, pesca, águas superficiais e agricultura.

Foram todos entrevistados em janeiro de 2013 e eram funcionários dos seguintes locais : Direção Geral de Meio Ambiente (DGE, em francês), Comuna de Crissier e Serviço de abastecimento de água de Lausanne. Análise dos resultados - Os resultados para cada indicador foram analisados de acordo com as repostas dos atores por uso segundo grades de avaliação. Tais grades consideraram a existência, intensidade e eficácia de cada indicador, de acordo com a classificação: muito bom (5), bom (4), regular (3), ruim (2), muito ruim (1) e sem resposta (0).

\section{A BACIA HIDROGRÁFICA MĖBRE-SORGE, CANTÃO DE VAUD, SUIÇA}

A bacia hidrográfica Mèbre-Sorge situa-se na zona oeste da área urbana de Lausanne, cantão de Vaud, Suíça. Ela é composta pelos rios Mèbre e Sorge, que se unem e formam o rio Chamberonne, a $1,5 \mathrm{~km}$ de sua desembocadura no lago Léman. Trata-se de uma bacia hidrográfica de tamanho pequeno, com uma superfície de $40,2 \mathrm{~km}^{2}$ e uma altitude média de $572 \mathrm{~m}$, (850 m no ponto mais elevado e $350 \mathrm{~m}$ no ponto mais baixo) (Jakob et al., 2007). Ela cobre (na maior parte dos casos parcialmente) o território de 21 comunas (Figura 1).

As comunas pertencentes à bacia hidrográfica situam-se em uma região com alto potencial de crescimento econômico e demográfico. De fato, esta região passou, nas últimas décadas, por uma urbanização rápida e dispersa das comunas, influenciadas pela adjacência à cidade de Lausanne (aproximadamente 5 $\mathrm{km}$ de distância). Esse rápido crescimento provocou problemas urbanos e ambientais ligados notadamente à densidade do tráfego e à poluição. De modo a responder a esses problemas, diferentes atores iniciaram, a partir de 2000 , estudos de ordenamento do território (Schémadirecteur de l'Ouestlausannois, 2003).

$\mathrm{O}$ uso do solo compreende uma parte mais povoada e urbanizada a jusante (em torno de $12 \mathrm{~km}^{2}$ ), onde a taxa de saturação da ocupação alcançava em 1996 os 80\% - 90\%, e uma área rural concentrada a montante da bacia hidrográfica (aproximadamente $28 \mathrm{~km}^{2}$ ) (Jarrar\&Consuegra, 1996). As coberturas florestais distribuem-se heterogeneamente sobretudo ao centro da bacia em questão.

\section{RESULTADOS E DISCUSSÃO}

Os indicadores foram aplicados de maneira a obter-se uma visão global dos usos na bacia hidrográfica e a observar se os atores consideram os múltiplos usos durante a tomada de decisão. Os valores de cada indicador segundo as respostas dos atores entrevistados podem ser visualizados na Tabela 1.

À partir das entrevistas realizadas, é possível perceber a falta de articulação entre os atores e os setores relativos à água. $\mathrm{Na}$ bacia hidrográfica estudada, não existe um acordo englobando todos os setores nem uma estrutura formal que favoreça tal integração. Entretanto, o processo de colaboração e articulação são variáveis segundo o uso.

No setor de tratamento de água e esgoto, l'EntenteintercommunaleMèbre-Sorge (Consórcio Intercomunal Mébre-Sorge, em português), foi criada em 1967 entre cinco comunas à jusante da bacia hidrográfica (Chavannes-près-Renens, Ecublens, Renens, Saint-Sulpice e Crissier, que a dirige) para organizarem juntos a coleta de suas águas residuais. Entretanto, essa instância autônoma confronta-se com problemas internos de ordem financeira. A repartição das despesas foi fixada durante sua criação e, desde então, Crissier assume $45 \%$ dos custos, Renens 30\%, Ecublens 15\%, Chavannes 11\% e Saint Sulpice 0,35\%. Entretanto, a repartição demográfica evoluiu desde então e Tinetta- 


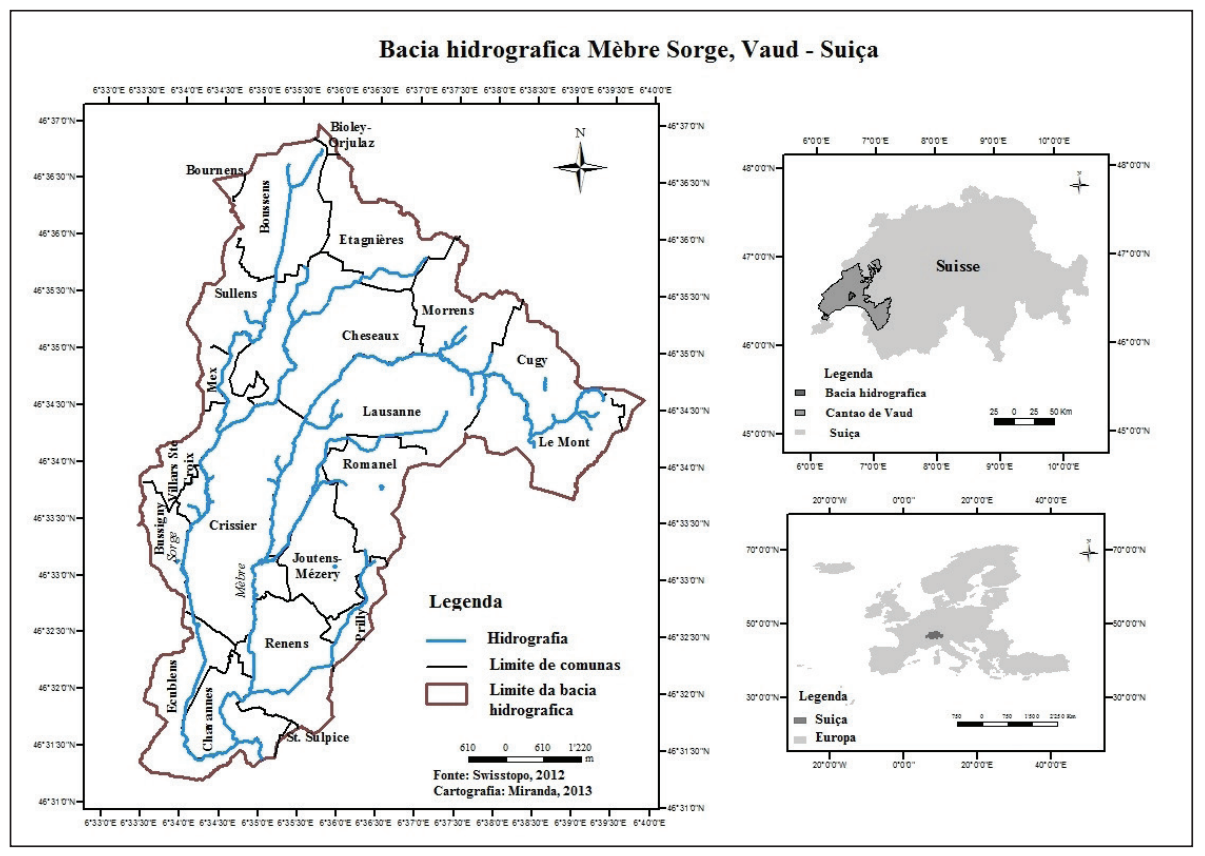

FIGURA 1. Localização da bacia hidrográfica Mèbre-Sorge no cantão de Vaud, Suíça.

Mystre, funcionária da comuna de Renens, afirma que não se sabe exatamente sobre qual base a repartição entre as comunas foi estabelecida. Atualmente, algumas comunas consideram a repartição como injusta. Por esse motivo, Chavannes recusou o orçamento para o ano de 2013 (Mendicino, 2013).

Um outro problema está ligado à participação de outras comunas no consórcio. Segundo Michel Tendon, presidente do consórcio, muitas comunas membros consideram que certas coletividades a montante deveriam participar dos custos dos coletores, já que aproveitam em parte do sistema.

Percebe-se uma ligação entre o setor supracitado e o de água potável, através de reuniões informativas realizadas uma vez por ano entre funcionários comunais e cantonais. Os outros setores não são considerados durante o processo de gestão. Fréderic Hoffman, responsável pelo setor de pesca no cantão, declarou que, atualmente, apenas alguns usos são prioritários em relação aos outros.

Segundo Emmanuel Poget, funcionário cantonal responsável por supervisionar o tratamento de água e esgoto na bacia Mèbre-Sorge, « não existe um especialista para cada domínio e não há integração entre eles ». Esse fato mostra-se evidente nas respostas dos setores de pesca (associações de pescadores), de agricultura (cantão) e das ONGs (VaudRando et Greenpeace Vaud) : os interlocutores não foram entrevistados, pois afirmaram não poder responder às questões sobre a gestão de águas, uma vez que não se ocupavam desta.

Uma tentativa de gerir a água à partir de uma visão global tratou-se da criação da Commission de gestiondesressourceseneau - GRE (Comissão de Gestão de Recursos Hídricos, em português) no cantão. Ela reagrupa membros de diferentes serviços referentes à utilização de água : empregados cantonais dos domínios de hidrologia, água potável e segurança contra incêndios. Seus membros se reúnem duas vezes por ano e objetivam propor soluções conjuntas considerando interesses de cada parte. Segundo Fréderic Hoffmann, membro da GRE, as atividades são : reflexões estratégicas sobre o abastecimento de água potável, regulamentação de autorizações de retirada de água para irrigação, supervisão de projetos transversais integrando a água (revitalização, regionalização de estações de tratamento). Entretanto, outros funcionários ligados ao setor de água do cantão desconhecem sua existência. O funcionamento dessa comissão representa, ainda assim, um caminho favorável à integração da gestão, pois nenhuma estrutura similar existe a nível regional. 
A formação dos atores institucionais varia segundo a função que eles desenvolvem. Existem desde técnicos com formação profissional técnica até doutores responsáveis por setores de análises ou chefes de seção. Nos setores de tratamento de água e esgoto e água potável, existe igualmente formações internas específicas segundo a função, não obrigatórias, mas disponíveis para todos os funcionários.

Existem leis específicas regulamentando cada uso em particular, mas a gestão integrada de recursos hídricos não é sustentada por regulamentação. O planejamento e o financiamento seguem esta mesma lógica. No setor de abastecimento básico, o financiamento é realizado independentemente por cada comuna, e existe o Plano Geral de Evacuação das Águas, ambos sem considerar a bacia hidrográfica. De acordo com Michel Poget, o cantão reflete atualmente sobre a realização de um Plano Regional de Evacuação das Águas (considerando a totalidade da bacia hidrográfica), mas, atualmente, é preciso realmente comprovar sua necessidade. Segundo o funcionário, os estudos acadêmicos poderiam ajudar o cantão nesta questão. Os responsáveis cantonais estão interessados por tal instrumento, mas politicamente é ainda um desafio. Como a gestão é feita por comunas, se passasse a ser realizada por bacia hidrográfica isto implicaria a perda de autonomia das comunas. O funcionário cantonal acrescenta que a lei deveria ser alterada para que a gestão fosse desempenhada por um sindicato intercomunal, por exemplo. Tal sindicato se ocuparia da estação de tratamento e recolheria todas as taxas das comunas, o que permitiria o financiamento de medidas importantes à escala da bacia hidrográfica.

Em relação à satisfação dos atores, todos os usos foram considerados: pesca, água potável, irrigação, lazer, saneamento básico e também a integração dos usos. Se o ator não correspondia diretamente a todos esses usos, o pedido justificou-se devido a compreensão do nível de conhecimento dos atores e interesse por outros usos.

Tratamento de água e esgoto - o setor foi considerado por todos os atores participantes deste estudo como regular a ruim. Entre os pontos problemáticos evocados nas entrevistas, percebe-se a necessidade de passar ao sistema separativo e adaptar as redes comunais (água limpa/água residual) e o financiamento pelas comunas.

Meio vital e pesca - os atores mostraram uma grande diversidade sobre a apreciação da qualidade dos corpos hídricos, de bom a ruim. O fato desta bacia hidrográfica ter a pior qualidade entre os rios que desembocam no lago Léman foi considerado por muitos atores como sendo inadmissível. Outros consideram que uma importante causa deste estado é a insuficiência das estações de tratamento de água. A bacia hidrográfica Mèbre-Sorge é fortemente influenciada pelas atividades humanas. A impermeabilização crescente do território cria uma certa inquietude em relação a enchentes. Os problemas ligados às redes de tratamento de água e esgoto e o desconhecimento quanto ao impacto das rodovias na rede são as principais preocupações dos responsáveis nas comunas. Entretanto, atualmente existem esforços e mobilização para diminuir a poluição dos rios e do lago Léman.

Agua potável - Todos os atores contatados estão de acordo com o fato de que a distribuição de água potável não causa preocupação a curto e a médio prazo. Aliás, o lago Léman constitui um reservatório potencial importante em caso de necessidade. A qualidade da água potável é considerada muito boa, de acordo com análises bioquímicas e físicas, sendo possível o consumo direto da água provinda do serviço de distribuição.

Lazer (paisagem e acesso aos rios) - nenhum ator ligado diretamente ao lazer foi abordado. De acordo com os outros atores, o valor do rio e o acesso aos mesmos podem ser qualificados como regulares a bons. Os corpos hídricos são muito frequentados e apreciados. Porém, a diversidade da fauna aquática sofre uma tendência à baixa nos últimos anos. A preservação dos biótopos aquáticos é boa, mas grandes esforços devem ser motivados para revitalizar as bordas do lago Léman e dos rios, segundo Fréderic Hoffman.

Integração dos usos - os atores consideram a integração entre os atores como regular a ruim. De acordo com estes, falta uma visão global para coordenar os usos e os atores. Primeiramente, a coordenação em cada setor apresenta frequentemente fraquezas: falta de colaboração, dificuldades na repartição de custos (como no setor de saneamento básico). Além disso, a gestão é essencialmente setorial, o que torna difícil a integração entre os usos.

Não existe um sistema que unifique e englobe os dados referentes aos temas de qualidade, quantidade e proteção das águas. Os dados existentes por setor são acessíveis por internet ou diante da administração cantonal ou communal e são, em alguns casos, cobrados.

Atualmente, o cantão melhora o acesso aos seus bancos de dados. O Sistema de Gestão de Recursos Hídricos do Cantão de Vaud (GESREAU) é um bom exemplo. Trata-se de uma ferramenta de consulta de dados por internet atualizado pela 
DirectionGénérale de l'Environnement (DGE) englobando a digitalização dos corpos hídricos cantonais, as seções transversais, as bacias de retenção, os trechos corrigidos e um inventário ecomorfológico (Vaud, 2013).

O laboratório da DGE dispõe de dados quantitativos, mas apenas uma parte deles é difundida, por falta de meios financeiros e pessoal suficiente $(\mathrm{Ru}-$ bin, 2012). Entretanto, certos dados biológicos dos corpos d'água de Vaud são regularmente coletados e divulgados (Vaud, 2012).

Em relação à água potável, o regulamento Ordonnancedu DFI de 23 de novembro de 2005 sobre água potável e água mineral estabelece o dever de informação, em que toda pessoa que explora infrastruturas de água potável deve informar os consumidores ao menos uma vez por ano sobre sua qualidade. Consequentemente, as comunas da bacia hidrográfica em questão colocam à disposição na internet resultados de análises microbiológicas e físico-químicas da água.

Enfim, os dados existentes são insuficientes e não englobam todos os usos. Os que estão presentes não são, entre a maioria, disponíveis na internet ou não o são gratuitamente.

As funções são claramente repartidas entre os níveis institucionais, segundo todos os atores contatados. Entretanto, as opiniões sobre o conhecimento e os meios adequados para sua realização são variadas.

O responsável pelo setor de tratamento de água e esgoto do cantão afirmou que as funções relativas à gestão dos recursos hídricos são realizadas pelas comunas sob controle cantonal. Mas estas recusam qualquer intervenção cantonal neste domínio. Entretanto, ele afirma que o cantão deveria ser mais diretivo na coordenação. Para o presidente da Entente IntercommunaleMèbre-Sorge, o cantão poderia ter um controle um pouco mais forte, com medidas incitativas. O cantão poderia, por exemplo, publicar os dados relativos às redes comunais de tratamento de água e esgoto e os financiamentos de cada comuna. Segundo outros responsáveis comunais, as competências e o financiamento dependem muito frequentemente da iniciativa das comunas, o que pode entravar o processo de gestão.

Em relação à colaboração entre os níveis institucionais, ela é considerada sobretudo entre o cantão e as comunas, seguindo as competências em matéria de gestão de águas. As comunas e o cantão possuem pouco contato em relação a todos os usos, exceto quando trata-se de solucionar os problemas pontuais. Os usos mais relacionados são tratamento de água e esgoto e qualidade de água, pelos quais as reuniões de informações são realizadas para resolver as principais questões na bacia hidrográfica Mèbre-Sorge.

\section{CONCLUSÃO}

Neste trabalho é apresentada a situação da gestão de recursos hídricos na Suíça, tendo como estudo de caso a bacia hidrográfica Mèbre-Sorge (cantão de Vaud) através da elaboração e aplicação de indicadores capazes de mostrar o nível de integração entre os usos, o meio ambiente e as escalas de gestão. A avaliação dos resultados foi baseada em entrevistas realizadas com atores ligados à bacia hidrográfica suíça.

O conceito de gestão integrada de recursos hídricos (GIRH) é muito discutido atualmente, mas mostra-se de difícil aplicação em escala local. Desta forma, esta pesquisa buscou compreender quais são os avanços e os desafios para sua efetivação.

A elaboração dos indicadores da integração de recursos hídricos foi possível através da bibliografia analisada e das entrevistas com os responsáveis institucionais pela gestão de águas nos cantões de Fribourg (pioneiro na aplicação da gestão integrada no país) e Vaud.

Os indicadores selecionados permitiram visualizar questões essenciais ligadas a GIRH : nível de colaboração entre os atores, impacto dos usos no meio ambiente, qualificação dos profissionais, tipo de financiamentos existentes, planejamento, banco de dados e cooperação entre os níveis institucionais.

A análise global do estudo de caso revela a falta de integração entre as variáveis consideradas de acordo com os indicadores formulados. Não há um organismo ou uma forma de acordo que se ocupe da gestão integrada de recursos hídricos no cantão de Vaud. A gestão é realizada por setores e, na bacia hidrográfica estudada, apenas os usos tratamento de água e esgoto e água potável revelaram uma estreita ligação entre os atores. Entretanto, os usos pesca, irrigação e lazer não são contemplados durante a gestão.

\section{AGRADECIMENTOS}

A pesquisa que resultou neste artigo foi financiada pela Confederação Suíça e orientada pelo Prof. Dr. Emmanuel Reynard, professor de Geografia Física e diretor do Institut de Géographie et Durabilité da Université de Lausanne. 


\section{Referências}

APPLETON, J; ALI, M.; COTTON, A. Success and sustainability indicators.A tool to assess primary Collection Schemes.A case study of Khulna, Bangladesh.LoughboroughUniversity, Leicestershire. 2000.

ARAUJO, D.; RIBEIRO, M.M.R.; CASTRO, Z.M.C. Conflitos Institucionais na Gestão dos Recursos Hidricos do Estado da Paraíba. Revista Brasileira de Recursos Hídricos. v. 17, p. 259-271, 2012.

BELL, S.; MORSE, S. $2^{\circ}$ ed. Sustainabilityindicators. Measuring the immeasurable. London: Earthscan publishes, 2008.

CANNEVA, G., GUÉRIN-SCHNEIDER, L. La construction des indicateurs de performance des services d'eau en France :mesurer le développement durable ? Natures Sciences Sociétés, v. 19, p. 213-223, 2011.

CHARNAY, B. Pour unegestionintégrée des ressources en eau surunterritoire de montagne. Le cas du basin versant du Giffre (Haute-Savoie). Annecy, Université de Savoie, 2010.

CONVENTION ALPINE. L'eauet la gestion des ressources en eau. Rapport surl'état des Alpes.Bolzano: Alpconv, 2009.

FAUCHEUX, S.; NICOLAI, I. La responsabilitésociétaledanslaconstruction d'indicateurs: l'expérience de l'industrieeuropéenne de l'aluminium. NaturesSciencesSociétés, v. 12, p. 30-41, 2004.

FRIBOURG. Loisurleseauxdu 18 décembre 2009 (LCEAeaux RSF 812.1). Disponível em : http://bdlf.fr.ch/frontend/versions/3281/ art26?locale=fr. Acesso em : 10 ago. 2013.

FRIBOURG. Règlementsur les eaux du 21 juin 2011 (RCEaux).Disponivel em : http://bdlf.fr.ch/frontend/versions/2180?locale=fr. Acesso em : 10 ago. 2013.

GENĖVE. Loisur les eaux du 5 juillet 1961 (LEaux-GE L2 05).Disponivel em : http://www.ge.ch/legislation/rsg/f/rsg_12_05.html. Acesso em: 10 ago. 2013.

GENĖVE. Traitésinternationauxet accords transfrontaliers. Disponivel em: http://www.geneve.ch/legislation/accords/f/accords_table_TI.html. Acesso em: 10 ago. 2013.

GWP. Integrated Water Resources Management. Global Water Partnership Technical Advisory Committee, Background Paper n. 4, 2000.

JAKOB A., PFAMMATTER F., SCHÄDLER M. Caractéristiques des bassins versants. In: Atlas hydrologique de laSuisse; planche 7.8. Office fédéral de l'environnement. Berne, 2007.

JARRAR, I.; CONSUEGRA, D. Étudehydrologiquedubassinversant de laMèbre-Sorge. IATE/HYDRAM - Hydrologie et aménagements. EcolePolytechniqueFédérale de Lausanne, 1996.

KENMOGNE, R. K.; ROSILLON, F.; MPAKAM, H. G.; NONO, A. Enjeuxsanitaires, socio-économiques et environnementauxliés à laréutilisationdeseauxuséesdanslemaraîchageurbain: casdubassinversant de l'Abiergué (Yaoundé-Cameroun). RevueVertigo, V. 10 n. 2, p. 1-10, 2010.

MENDICINO, C. Rupture d'entente autourdeseauxusées de l'Ouest. 24 heures, Lausanne. Lausanne t région, p. 20, 16 jan. 2013.

OFEV. Gestion des eaux en Suisse Situation actuelleetthèses. Berne: Office fédéral de l'environnement, 2007a.

OFEV. Description etanalysed'exemples de gestionintégrée par bassin versant (GIB). Berne: Office fédéral de l'environnement, 2007b.

OFEV. Gérerlespénurieslocales d'eauenSuisse. RapportduConseilfédéralenréponseaupostulat "Eau et agriculture. Lesdéfis de demain". Berne: Office fédéral de l'environnement, 2010.

OFEV. Gestion par bassin versant - idéesdirectrices. Berne: Office fédéral de l'environnement, 2011.

OFEV. Gestion par bassin versant. Guide pratique pour unegestionintégrée des eaux en Suisse. Berne: Office fédéral de l'environnement, 2012. OFEV. Guide de coopération eau pour les communes. Unissonsnos talents. Berne: Office fédéral de l'environnement, 2013.

PNUMA. Metodologia para laelaboración de los informes GEO Ciudades: manual de Aplicación. México: Programa de Naciones Unidas para elMedio Ambiente, 2003.

REYNARD, R. Transporterl'eau : regardscroiséssurlesréseauxurbains et ruraux de l'eauenSuisse. Flux, v. 2-3, n. 72, p. 27-38, 2008.

RUBIN, J.F. La naturedemainmilieuxaquatiques. Rapport final. Lausanne: ECOSCAN SA, 2012

SOUTO, R.D. 2012. Atlas de Indicadores de Sustentabilidade para os Municípios Costeiros do Estado do Rio de Janeiro. Disponivel em: http://www.ivides.org/atlas Acesso em: 20 mar. 2013.

VAUD. Schémadirecteur de l'Ouestlausannois. Lausanne : Bureau directeurduschémadirecteur de l'Ouestlausannois, 2003.

VAUD (Cantão). 2012. Qualitébiologiquedescours d'eauvaudois : suivis 2008-2011. Disponível em: http://www.vd.ch/fileadmin/user_upload/ themes/environnement/eau/fichiers_pdf/qualite_bi

ologique_rivieres_2008-2011.pdf. Acesso em: 11 ago 2013.

VAUD. 2013. Geoportail des lacsetcoursd'eau. Disponivel em: http://www.gesreau.vd.ch/. Acesso em: 11 ago 2013.

VAN BELLEN, H. M. Indicadores ambientais no Brasil: aspectos ecológicos, de eficiência e distributivos. Rio de Janeiro: Editora FGV, 2006.

Graziele Muniz Miranda Université de Lausanne, Institut de géographie et durabilité (IGD).E-mail: gmunizmi@unil.ch 